\title{
A mathematical model for planning transportation of multiple petroleum products in a multi-pipeline system
}

\author{
A. Herrán ${ }^{a, *}$, J.M. de la Cruz ${ }^{b}$, B. de Andrés ${ }^{b}$ \\ a Department of Computer Science Engineering (CES Felipe II), Complutense University, 28300 Aranjuez, Spain \\ ${ }^{\mathrm{b}}$ Department of Computer Architecture and Automatic Control, Complutense University, 28040 Madrid, Spain
}

\section{A R T I C L E I N F O}

\section{Article history:}

Received 22 December 2008

Received in revised form 8 November 2009

Accepted 15 November 2009

Available online 24 November 2009

\section{Keywords:}

Multiproduct pipeline

Multi-pipeline system

Transportation

Planning and scheduling

Discrete approach

Mixed-integer linear program

\begin{abstract}
A B S T R A C T
A multiproduct pipeline provides an economic way to transport large volumes of refined petroleum products over long distances. In such a pipeline, different products are pumped back-to-back without any separation device between them. Sometimes, multiproduct pipelines can be connected together, resulting in a more complex system commonly named multi-pipeline system. This paper proposes a new discrete mathematical approach to solve short-term operational planning of multi-pipeline systems for refined products. This model is based on a discrete approach that divides both the planning horizon into time intervals of equal duration and the individual polyducts into packages of equal volume each containing a single product. Numerical examples are solved in order to show the performance of the proposed model. All the instances are implemented with the OPL modeling language running CPLEX as solver.
\end{abstract}

(c) 2009 Elsevier Ltd. All rights reserved.

\section{Introduction}

Pipelines have been a widely used mode of transportation for petroleum products and their derivatives for the last 40 years. The annual transportation cost in the Petroleum Industry usually surpasses billions of dollars, since large volumes have to be transported over long distances. Evidently, pipeline systems play an important role in the industry. Although the initial capital investment required to setup these transportation systems is high, the operating costs are very low compared to other transportation modes such as rail and highway. Even so, the final price of the product depends on its transportation cost, making the optimization of the transportation process a problem of extreme relevance. Consequently, the related scheduling activities for product distribution using pipeline systems have been a focus for at least 30 years.

The simplest pipeline has one source, one destination, and one type of product to be delivered, e.g. the pipelines used in the transportation of crude oil from coastal ports to inland refineries. At the next level of complexity, the pipeline could have multiple destinations; and a more realistic pipeline would also handle multiple petroleum products treated in refineries such as kerosene, naphtha, and gas oil (Sasikumar, Prakash, Patil, \& Ramani, 1997).

\footnotetext{
* Corresponding author.

E-mail address: aherrang@fis.ucm.es (A. Herrán).
}

These multiproduct pipelines are commonly named polyducts. In a polyduct, different products are pumped back-to-back without any separation devices between them, as shown in Fig. 1.

The main challenge in operating polyduct systems is planning the optimal sequence, length and starting time of each pumping run from the refinery to the pipeline, together with the optimal timing of transferring these products from the pipeline to each depot. The complexity of this optimization process arises from the typical operational aspects of these systems. Since there is no physical separation between different products as they move through the pipeline, some mixing and consequent contamination at product interface is inevitable. These product mixtures are called transmixes and they cannot be simply discarded. They must pass through a special treatment that usually involves sending them back to a refinery for reprocessing; the cost associated to this process is very high (Techo \& Holbrook, 1974). The degree of these interface losses depends on the products that come in contact inside the pipeline segment. Moreover, if two products are known to generate high interface losses, the pumping schedule must avoid pumping them back-to-back into the pipeline. Another consequence of transmixes is that pumping small quantities of products is not economical. Hence, each pumping run must fulfill a minimum length to make the pumping schedule efficient. Finally, the pumping schedule must take into account the product availability at the refinery and the consumption of different products at each depot.

All the different aspects mentioned above make the pumping schedule of multiple petroleum products from a single refinery 


\section{Nomenclature \\ Sets \\ $C \quad$ set of connections indexed by $c=1, \ldots, \operatorname{card}(C)$ \\ $C B \quad$ set of connections pairs $\left\{\left(c, c^{\prime}\right), \ldots\right\}$ representing reversible polyducts \\ $\mathrm{CI}_{n} \quad$ set of incoming connections at node $n$ \\ $\mathrm{CO}_{n}$ set of outgoing connections at node $n$ \\ $L_{c} \quad$ set of pipeline segments at each connection $c$ indexed by $b=1, \ldots, \operatorname{card}\left(L_{c}\right)$ \\ $N \quad$ set of nodes indexed by $n=1, \ldots, \operatorname{card}(N)$ \\ $N D$ subset of destination nodes indexed by $n=\operatorname{card}(N S)+\operatorname{card}(N I)+1, \ldots, \operatorname{card}(N)$ \\ NI subset of intermediate nodes indexed by $n=\operatorname{card}(N S)+1, \ldots, \operatorname{card}(N S)+\operatorname{card}(N I)$ \\ NS subset of source nodes indexed by $n=1, \ldots$, $\operatorname{card}(N S)$ \\ $P \quad$ set of different petroleum derivatives indexed by $p=1, \ldots, \operatorname{card}(P)$ \\ $S \quad$ set of product pairs $\left\{\left(p, p^{\prime}\right), \ldots\right\}$ representing forbid- den pumping sequences \\ $T \quad$ set of time periods in the planning horizon indexed by $t=1, \ldots, \operatorname{card}(T)$}

\section{Parameters}

$A 0_{n, p} \quad$ inventory level of product $p$ at node $n$ at the beginning of the planning horizon

$\operatorname{Amax}_{n, p}$ maximum allowed inventory level of product $p$ at node $n$

$\operatorname{Amin}_{n, p}$ minimum allowed inventory level of product $p$ at node $n$

$C A_{n, p} \quad$ unit inventory cost for product $p$ at node $n$

$\mathrm{CI}_{c, p} \quad$ unit pumping cost to deliver a package containing product $p$ from its source to its destination through connection $c$

$C T_{c} \quad$ start/stop cost at each polyduct (connection $c$ ) of the network

$C R_{p, p^{\prime}} \quad$ unit reprocessing cost of interface material involving different products $p$ and $p^{\prime}$

$D M_{n, p} \quad$ demand of product $p$ at node $n$ at the end of the planning horizon

$\Delta \quad$ period length in hours

$Q_{t, n, p} \quad$ scheduled production of product $p$ in refinery $n$ at period $t$

QMmax maximum volume of product that can be supplied to a local market

$\mathrm{So}_{c} \quad$ binary parameter denoting if connection $c$ is pumping some product at the beginning of the planning horizon

$V C_{p, p^{\prime}} \quad$ interface volume between packages pumped consecutively through the same polyduct containing products $p$ and $p^{\prime}$

$V P \quad$ unit package volume in $\mathrm{m}^{3}$

$x o_{c, b, p} \quad$ binary parameter denoting if portion $b$ of connection $c$ is occupied by a package containing product $p$ at the beginning of the planning horizon

\section{Variables}

$a_{t, n, p} \quad$ inventory level of product $p$ at node $n$ at period $t$

$q m_{t, n, p}$ amount of product $p$ transferred at period $t$ from destination node $n$ to its local market

$s_{t, c} \quad$ binary variable denoting if a package is pumped through connection $c$ at period $t$ $v_{t, c, p, p^{\prime}} \quad$ interface volume between the package pumped at period $t$ through connection $c$ and the package occupying the first portion of the same connection if they contains products $p$ and $p^{\prime}$, respectively

$x_{t, c, b, p} \quad$ binary variable denoting if portion $b$ of connection $c$ is occupied by a package containing product $p$ at period $t$

$y_{t, c, p} \quad$ binary variable denoting if the package pumped through connection $c$ at period $t$ contains product $p$

to multiple destinations a complex activity. A few papers have been published on this subject in the last decade. The optimization techniques reported in these papers can be categorized as knowledge-based search heuristics and mathematical programming approaches, where the latter can be further classified as discrete or continuous-time based models. Sasikumar et al. (1997) presented a knowledge-based heuristic search technique providing a monthly pumping schedule to minimize interface and pumping costs. The heuristic search also took into account several problem constraints such as product availability, demand satisfaction, inventory limits and other logical pipeline operational constraints. Rejowski and Pinto (2003) developed a discrete-time MILP model for the scheduling of a real-world multiproduct pipeline system with multiple destinations. Four products: gasoline, diesel oil, liquefied petroleum gas (LPG) and jet fuel were considered. Two models based on disjunctive programming and on discrete-time representation were presented. The first one proposes dividing the pipeline into packages of equal size, while the second one does not. The total cost to be minimized includes inventory, pumping and interface costs. Key decisions involve loading and unloading operations of depots and the pipeline. Results include the inventory levels at all locations, the operations of all segments of the pipeline and the best sequencing of products inside the pipeline. Rejowski and Pinto (2004) developed a model to improve the computational efficiency from their previous work (Rejowski \& Pinto, 2003). Special and non-intuitive practical constraints were added to the original MILP. The resulting model was analyzed in terms of computational performance and solution quality. Additionally, the same authors (Rejowski \& Pinto, 2008) developed a novel continuous-time representation to model the same process considered in their previous papers. On the other hand, Cafaro and Cerdá (2004) developed a continuous-time MILP model for the scheduling of a single pipeline transporting several refined petroleum products from an oil refinery to several distribution terminals. Batch sizing and sequencing are optimally selected by the model to meet all product demands at minimum cost over a single planning period. The approach accounts for slug sequencing constraints, forbidden slug sequences, mass balances, pipeline and depot loading and unloading operations, depot permissible levels and feasibility conditions for transferring material from pipeline slugs to depots. The objective is to minimize pumping, inventory and transportation costs while satisfying all problem constraints. Transportation costs include material losses and interface reprocessing costs at the depots. In a subsequent work, Cafaro and Cerdá (2008) extended their formulation considering multiple delivery due dates. Recently, other authors, i.e. Mirhassani and Ghorbanalizadeh (2008) developed an integer programming formulation to deal with the same problem.

All the papers reviewed above consider the pumping schedule of multiple products for a single pipeline system. However, the polyducts in a specific geographical area (region, country, etc.) are connected together, resulting in a more complex system 


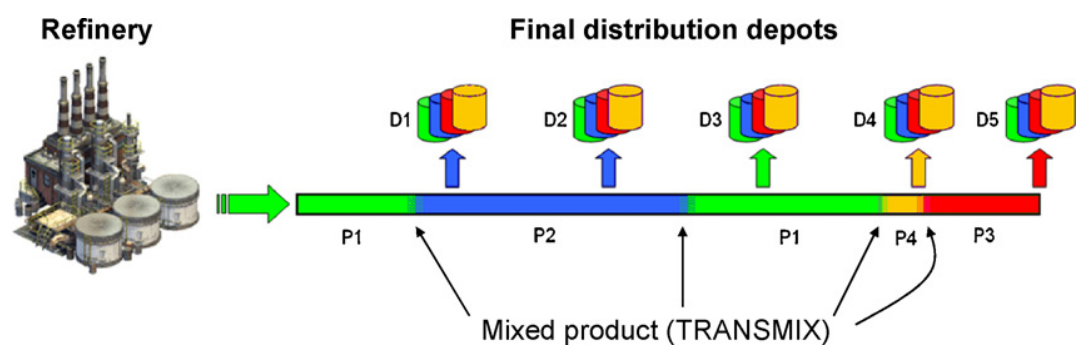

Fig. 1. Typical operation of a polyduct system.

commonly named multi-pipeline system (Cruz, Andrés, Herrán, Besada, \& Fernández, 2003; Cruz, Herrán, Risco, \& Andrés, 2005). In these systems, several pumps are strategically distributed along the network in order to move the products to their destinations. Hence, from an operative point of view, a polyduct network is composed of a set of nodes with storage and pump capacity and a set of polyducts interconnecting these nodes. These polyducts are mostly unidirectional but, for operative flexibility reasons, they could also be reversible. The network topology depends on the oil activity and the conditions at each geographical area. Fig. 2 shows an example of a multi-pipeline system. This network has two source nodes ( 1 and 2 ), two intermediate nodes ( 3 and 4 ) and three destination nodes (5, 6 and 7). Moreover, the product can flow in both directions through the reversible polyduct joining nodes 3 and 4 . Source nodes could be refineries or other supply systems, for example ports. Destination nodes are the final distribution centers with a specific demand that has to be fulfilled at the end of each planning horizon. Intermediate nodes ( 3 and 4 ) distribute the product received from the sources to the destinations in order to meet demands at these points.

On a logistic level, the problem is to plan the way in which different products are temporally transported from source nodes to destination nodes, passing through intermediate nodes in order to meet product demands at all pipeline depots before the end of the planning horizon. Furthermore, constraints related to the product availability at each source node must be dealt with, and proper physical conditions after network utilization, namely maximum/minimum inventory levels, must be satisfied. An optimal planning should also tend to reduce the number of product interfaces in order to lose as little as possible via product contamination. This paper proposes both a mathematical formulation to model these systems and a solution using MILP. The remainder of this paper is organized as follows: Section 2 shows the problem description. Section 3 shows the proposed model together with a simplified model that, under certain operative conditions, can be derived from the original one. In Section 4, two numerical examples are presented to show the utility of the proposed MILP models. Finally, conclusions are shown in Section 5.

\section{Problem description}

This paper considers a simplified model of an actual network. The pipeline network under study can be initially represented by a set of nodes $(N)$, connections $(C)$ and products $(P)$, whose activity is determined by a time interval $T$ (planning horizon) in which the demand must be fulfilled. Regarding the network components $N=N S \cup N I \cup N D$ is the set of nodes, where NS, NI and $N D$ are the subsets of source, intermediate and destination nodes, respectively. $C$ is the set of the network connections and $C B$ is the two-dimensional subset of the reversible ones. Also, $C I_{n}$ is defined as the subset of incoming connections to node $n$ and $\mathrm{CO}_{n}$ is defined as the outgoing ones. As an example, the network shown in Fig. 2

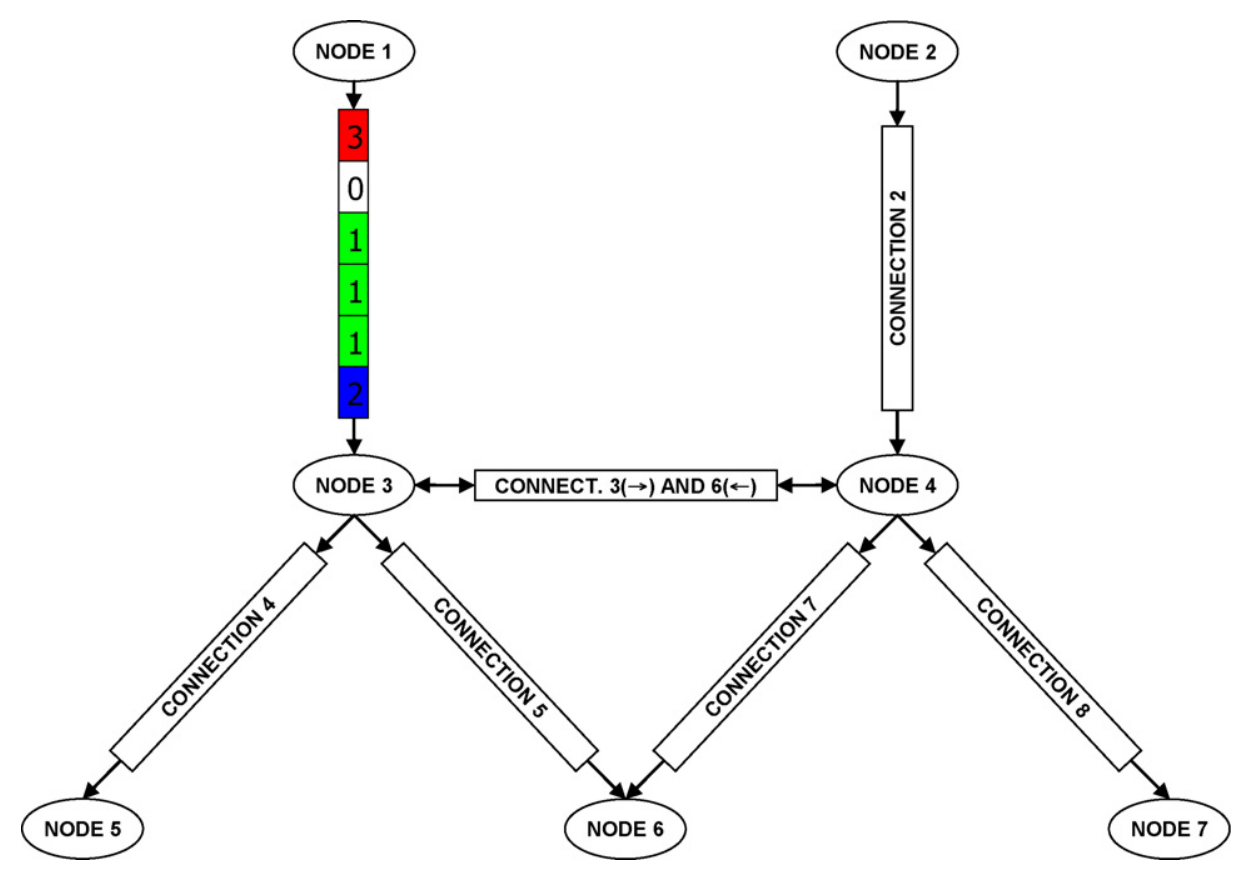

Fig. 2. Multi-pipeline system model. 


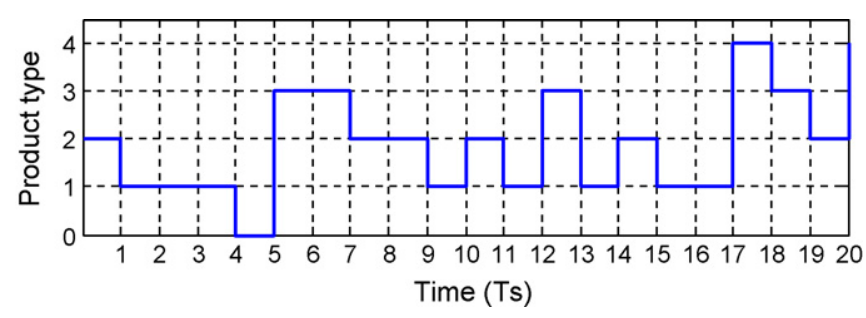

Fig. 3. Pumping sequence.

has $C=\left\{c_{1}, c_{2}, c_{3}, c_{4}, c_{5}, c_{6}, c_{7}, c_{8}\right\}$ and $C B=\left\{\left(c_{3}, c_{6}\right),\left(c_{6}, c_{3}\right)\right\}$, and the third node has $\mathrm{CI}_{3}=\left\{c_{1}, c_{6}\right\}$ and $\mathrm{CO}_{3}=\left\{c_{3}, c_{4}, c_{5}\right\}$.

Product balance at intermediate nodes is the most difficult process to model in this problem. This is due to the fact that intermediate nodes can not only receive but also send products at any time instant. As it will be seen in the next section, this process can be easily modeled assuming a discrete transport approach. It is based on the following assumption: the type of product pumped by each source or intermediate node can only change at some predefined time instants $t=0 \Delta, 2 \Delta, 3 \Delta, \ldots, T \Delta$, where $\Delta$ is the time duration of each pumping run. Hence, the planning horizon is discretized into a number of periods of length $\Delta$. An example of a pumping sequence of different products through a single pipeline is shown in Fig. 3. Thus, fluid transportation can be seen as the transport of discrete packages. Each package contains the amount of product continuously pumped into the pipeline during one period. Fig. 4 shows the temporal evolution of different packages inside of a polyduct for the pumping sequence shown in Fig. 3. Each cylindrical segment represents the volume occupied by a package inside the polyduct and is also the unit employed to measure the polyduct length. So, the polyduct length is divided into as many segments as the number of packages that the polyduct can store. As a result of product incompressibility, when a new package is pumped into the pipeline all the packages inside move one segment. Obviously, in a fixed planning schedule, as $\Delta \rightarrow 0$ this approach tends to a continuous transportation mode, with the associated increase of the number of variables.

Fig. 4 shows a stop on the pumping sequence at period 4 . Such pumping stoppage and the next pumping start at period 5 lead to a high operational cost. In addition, the interface losses are higher when the flow in the network is started or stopped, due to the transient rate of flow which occurs until it reaches a steady state. As a consequence, an optimal pumping schedule should only use stops when strictly necessary: this includes reversal of the pumping direction at reversible polyducts or a stoppage of the pumping sequence due to inventory availability.
In order to simplify the problem it is assumed that all polyducts have the same diameter and characteristics and that all products flow with the same speed occupying a similar volume in the polyduct. A crucial aspect of this kind of transportation system is that each polyduct must always be full. It forces a continuity of flow which implies that local changes in the sequence of inputs have impacts on the sequence of deliveries that are far apart in terms of distance and time. Every node of the network has depots to store many different products. Moreover, every depot has a maximum and minimum inventory level specified in terms of the number of packages that it can store. To summarize the problem description the following information is given:

- Network configuration: number of source, intermediate and destination nodes, number of polyducts and their length, connection topology and number of products.

- The initial state of the network and the length of the planning horizon.

- Scheduled production at each refinery according to the planning horizon.

- Maximum/minimum allowed product inventory for each depot at each node.

- Product inventory at each node at the beginning of the planning horizon.

- Product demand to be satisfied at each consumer node at the end of the planning horizon.

- Cost associated to each operation process in the network.

In addition, the following assumptions are made:

- Each individual pipeline is composed of an integral number of packages, all of which feature the same volume and contain single product.

- Each package is injected at the same pump rate regardless of the product that it contains. In this way, the planning horizon can be divided into an integral number of time intervals featuring the same length.

- Direct transfer of product packages between consecutive pipelines is not allowed.

- Every package of product pumped into an individual pipeline comes from the tank farm of a depot located at the pipeline inlet.

- Simultaneous package injections into several pipelines from the same source or intermediate depot located at their common inlet are permitted.
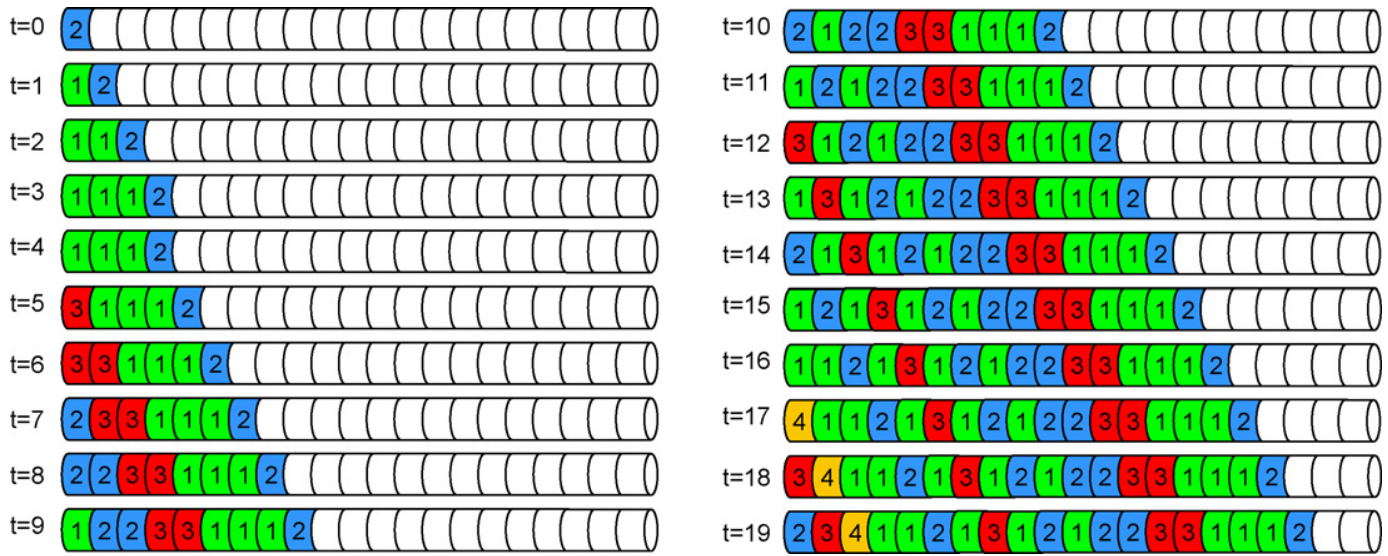

Fig. 4. Pipeline state associated to the pumping sequence shown in Fig. 3. 
- Every product demand at all pipeline depots must be satisfied before the end of the planning horizon.

- Shutdown and restarting operations for each individual pipeline have a finite cost that can change with the polyduct.

The objective is to establish the optimal sequence of products assigned to each new package pumped through each polyduct of the network in order to: (1) meet product demands at each destination node before the end of the planning horizon; (2) keep inventory levels in each node within its permissible range; and (3) minimize the pumping cost, start/stop cost, interface losses, and inventory carrying costs. At the same time, the inventory levels in each node must be tracked over the planning period, and forbidden product sequences must be avoided.

\section{Model development}

In order to solve this problem it is necessary to develop a mathematical model composed of an objective function and a set of constraints. This section shows equations using the nomenclature defined in this paper, resulting in a MILP that can be solved with any commercial solver.

\subsection{Objective function}

The objective function of the model, given in Eq. (1) below, comprises four different terms. The first one is the pumping cost, with a different cost factor $C_{c, p}$ for each connection and product. The second term is the start/stop cost of each polyduct, with a different cost factor $C T_{c}$ for each connection. The third term is the reprocessing cost of the interface volume between adjacent packages with different products $p$ and $p^{\prime}$. It has a different cost factor depending on the products $p$ and $p^{\prime}$ and the interface volume could also vary. Finally, the last term stands for the cost of holding product inventory in each node of the network (refineries, intermediate stations and consumer nodes). The cost factor $C A_{n, p}$ is different for each node and product:

$$
\begin{aligned}
\min z= & \sum_{t=1}^{T} \sum_{c=1}^{C} \sum_{p=1}^{P} C I_{c, p} \cdot V P \cdot y_{t, c, p}+\sum_{c=1}^{C} C T_{c} \cdot\left|s o_{c}-s_{1, c}\right| \\
& +\sum_{t=2}^{T} \sum_{c=1}^{C} C T_{C} \cdot\left|s_{t-1, c}-s_{t, c}\right| \\
& +\sum_{t=1}^{T} \sum_{c=1}^{C} \sum_{p=1}^{P} \sum_{p^{\prime}=1}^{P} C R_{p, p^{\prime}} \cdot v_{t, c, p, p^{\prime}} \\
& +\sum_{t=1}^{T} \sum_{n=1}^{N} \sum_{p=1}^{P} C A_{n, p} \cdot \Delta \cdot V P \times a_{t, n, p}
\end{aligned}
$$

\subsection{Model constraints}

The model has also a set of constraints that have been grouped in the following subsets:

- Constraints related to the pumping of new packages through each polyduct of the network. Eq. (2) states that only one package entering a polyduct per period is allowed. Eq. (3) avoids the simultaneous usage of both sending directions in reversible polyducts. It fixes the maximum number of packages (in this case 1 ) that can be pumped through both connections belonging to a reversible polyduct at each period. Interface volume between adjacent packages with different products is considered in Eq. (4). Moreover, because of high product contamination, some product sequences are not allowed. This feature is added to the problem formulation through Eq. (5), where $S$ is the set of forbidden sequences:

$$
\begin{aligned}
& \sum_{p=1}^{P} y_{t, c, p} \leq 1 \quad ; \quad \forall(t, c) \\
& \sum_{p=1}^{P}\left(y_{t, c, p}+y_{t, c^{\prime}, p}\right) \leq 1 \quad ; \quad \forall\left(t, c, c^{\prime}\right):\left(c, c^{\prime}\right) \in C B \\
& v_{t, c, p, p^{\prime}} \geq V C_{p, p^{\prime}} \cdot\left(x_{t-1, c, 1, p}+y_{t, c, p^{\prime}}-1\right) \quad ; \quad \forall\left(t, c, p, p^{\prime}\right): t>1 \\
& v_{1, c, p, p^{\prime}} \geq V C_{p, p^{\prime}} \cdot\left(x o_{c, 1, p}+y_{1, c, p^{\prime}}-1\right) \quad ; \quad \forall\left(c, p, p^{\prime}\right) \\
& v_{t, c, p, p^{\prime}} \geq 0 \quad ; \forall\left(t, c, p, p^{\prime}\right) \\
& x_{t-1, c, 1, p}+y_{t, c, p^{\prime}} \leq 1 \quad ; \quad \forall\left(t, c, p, p^{\prime}\right): t>1,\left(p, p^{\prime}\right) \in S \\
& x o_{c, 1, p}+y_{1, c, p^{\prime}} \leq 1 \quad ; \quad \forall\left(c, p, p^{\prime}\right):\left(p, p^{\prime}\right) \in S
\end{aligned}
$$

- Constraints related to the exact placement of each package pumped into the network. Initial placement of each package into the network is given by the parameter $x o_{c, b, p}$. If a package is pumped through connection $c$ at period $t$, the value of variable $s_{t, c}$ is set to 1 according to Eq. (6). Because of the product incompressibility, if $s_{t, c}=1$ the package pumped at period $t$ through connection $c$ pushes all the packages in the same polyduct to the next segment of the polyduct. This package movement is translated to the problem formulation by Eqs. (7) and (8). Eq. (7) applies to all the polyducts while Eq. (8) only applies to the reversible ones. Finally, if $s_{t, c}=0$ no package movement takes place at connection $c$ at period $t$, and all packages at this connection remain at the same position as they were at the previous period. This condition is stated by Eqs. (9) and (10) for unidirectional and reversible polyducts, respectively. Note that depending on the value of $s_{t, c}$ some of the constraints in Eqs. (7)-(10) are inactive:

$$
\begin{aligned}
& s_{t, c}=\sum_{p=1}^{P} y_{t, c, p} \quad ; \quad \forall(t, c) \\
& x_{t, c, b, p} \leq x_{t-1, c, b-1, p}-\left(s_{t, c}-1\right) \\
& x_{t, c, b, p} \geq x_{t-1, c, b-1, p}+\left(s_{t, c}-1\right) \quad ; \quad \forall(t, c, b, p): t>1, b>1 \\
& x_{1, c, b, p} \leq x o_{c, b-1, p}-\left(s_{1, c}-1\right) \\
& x_{1, c, b, p} \geq x o_{c, b-1, p}+\left(s_{1, c}-1\right) \\
& x_{t, c, 1, p} \leq y_{t, c, p}-\left(s_{t, c}-1\right) \\
& x_{t, c, 1, p} \geq y_{t, c, p}+\left(s_{t, c}-1\right) \\
& \begin{array}{l}
x_{t, c, b, p} \leq x_{t-1, c, b+1, p}-\left(s_{t, c^{\prime}}-1\right) \\
x_{t, c, b, p} \geq x_{t-1, c, b+1, p}+\left(s_{t, c^{\prime}}-1\right)
\end{array} \quad ; \quad \forall\left(t, c, c^{\prime} b, p\right): t>1,\left(c, c^{\prime}\right) \in C B, b<L_{c} \\
& x_{1, c, b, p} \leq x o_{c, b+1, p}-\left(s_{1, c^{\prime}}-1\right) \\
& x_{1, c, b, p} \geq x o_{c, b+1, p}+\left(s_{1, c^{\prime}}-1\right) \\
& x_{t, c, L_{c}, p} \leq y_{t, c^{\prime}, p}-\left(s_{t, c^{\prime}}-1\right) \\
& x_{t, c, L_{c}, p} \geq y_{t, c^{\prime}, p}+\left(s_{t, c^{\prime}}-1\right) \\
& \text {; } \forall\left(c, c^{\prime} b, p\right):\left(c, c^{\prime}\right) \in C B, b<L_{c} \\
& \text {; } \forall\left(t, c, c^{\prime}, p\right): t>1,\left(c, c^{\prime}\right) \in C B \\
& x_{t, c, b, p} \leq x_{t-1, c, b, p}+s_{t, c} \\
& x_{t, c, b, p} \geq x_{t-1, c, b, p}-s_{t, c} \\
& x_{1, c, b, p} \leq x o_{c, b, p}+s_{1, c} \\
& x_{1, c, b, p} \geq x o_{c, b, p}-s_{1, c} \\
& x_{t, c, b, p} \leq x_{t-1, c, b, p}+\left(s_{t, c}+s_{t, c^{\prime}}\right) \\
& x_{t, c, b, p} \geq x_{t-1, c, b, p}-\left(s_{t, c}+s_{t, c^{\prime}}\right) \\
& x_{1, c, b, p} \leq x o_{c, b, p}+\left(s_{1, c}+s_{1, c^{\prime}}\right) \\
& x_{1, c, b, p} \leq x o_{c, b, p}-\left(s_{1, c}+s_{1, c^{\prime}}\right) \\
& \begin{array}{l}
; \forall(t, c, b, p): t>1, c \notin C B \\
; \forall(c, b, p): c \notin C B \\
; \forall(t, c, b, p): t>1,\left(c, c^{\prime}\right) \in C B \\
; \quad \forall(c, b, p):\left(c, c^{\prime}\right) \in C B
\end{array}
\end{aligned}
$$


- Constraints are needed to keep track of the inventory level along the planning horizon. Each time a node pumps or receives a new package its inventory level, $a_{t, n, p}$, changes. This variable must be kept within its maximum and minimum allowed levels for each node. This condition is stated by Eq. (11). In order to satisfy this constraint the value of $a_{t, n, p}$ has to be correctly calculated for each period. Eq. (12) shows the constraints that must be added to the problem formulation to model the temporal evolution of inventory levels at source nodes. As it can be seen, the first constraint is a balance equation, whereas the second one applies only to the first period making use of $A 0_{n, p}$. Finally, Eqs. (13) and (14) are similar to Eq. (12) but for intermediate and destination nodes, respectively.

$$
\begin{aligned}
& \operatorname{Amin}_{n, p} \leq a_{t, n, p} \leq \operatorname{Amax}_{n, p} \quad ; \quad \forall(t, n, p): n \in N \\
& a_{t, n, p}=a_{t-1, n, p}-\sum_{c \in C O_{n}} y_{t, c, p}+Q_{t, n, p} \quad ; \quad \forall(t, n, p): t>1, n \in N S \\
& a_{1, n, p}=A 0_{n, p}-\sum_{c \in C O_{n}} y_{1, c, p}+Q_{1, n, p} \quad ; \quad \forall(n, p): n \in N S \\
& a_{t, n, p}=a_{t-1, n, p}-\sum_{c \in C O_{n}} y_{t, c, p}+\sum_{c \in C_{n}} x_{t-1, c, L_{c}, p} \cdot s_{t, c} \quad ; \quad \forall(t, n, p): t>1, n \in N I \\
& a_{1, n, p}=A 0_{n, p}-\sum_{c \in C O_{n}} y_{1, c, p}+\sum_{c \in C_{n}} x o_{c, L_{c}, p} \cdot s_{1, c} \quad ; \quad \forall(n, p): n \in N I \\
& a_{t, n, p}=a_{t-1, n, p}+\sum_{c \in C_{n}} x_{t-1, c, L_{c}, p} \cdot s_{t, c}-q m_{t, n, p} \quad ; \quad \forall(t, n, p): t>1, n \in N D \\
& a_{1, n, p}=A 0_{n, p}+\sum_{c \in C C_{n}} x O_{c, L_{c}, p} \cdot s_{1, c}-q m_{1, n, p} \quad ; \quad \forall(n, p): n \in N D
\end{aligned}
$$

- Fulfillment of market demands. The amount of product transferred from each destination node to its local market must be high enough to meet the market demands according to Eq. (15). Moreover, the maximum flow rate at which this amount can be delivered to the local market is limited by Eq. (16):

$$
D M_{n, p}=\sum_{t=1}^{T} q m_{t, n, p} \quad ; \quad \forall(n, p): n \in N D
$$

$0 \leq q m_{t, n, p} \leq Q M \max \quad ; \quad \forall(t, n, p): n \in N D$

- Linearization of nonlinear terms. Since Eqs. (1), (13) and (14) are nonlinear equations, a linearization process is needed in order to get a MILP model, which can be easily solved by a standard solver for instance CPLEX. The first nonlinearity appears in the second term of Eq. (1) as the absolute value of two binary variables. This term can be easily linearized by incorporating additional non-negative real variables $f$ defined as in Eq. (17) together with the necessary constraints, shown in Eq. (18), to make both models (linear and nonlinear) equivalent:

$$
\begin{aligned}
& f_{t, c}=\left|s_{t-1, c}-s_{t, c}\right| \quad ; \quad \forall(t, c): t>1 \\
& f_{1, c}=\left|s o_{c}-s_{1, c}\right| \quad ; \quad \forall(c) \\
& -f_{t, c} \leq s_{t-1, c}-s_{t, c} \leq f_{t, c} \quad ; \quad \forall(t, c): t>1 \\
& -f_{1, c} \leq s o_{c}-s_{1, c} \leq f_{1, c} \quad ; \quad \forall(c)
\end{aligned}
$$

The second nonlinearity appears in the first term of Eqs. (13) and (14) as the product of two binary variables ( $x$ and $s$ ). Such a term can be easily linearized by incorporating additional nonnegative real variables: $e$ defined as in Eq. (19). Furthermore, the constraints shown in Eq. (20) are needed to make both models (linear and nonlinear) equivalent:

$e_{t, c, p}=x_{t-1, c, L_{c}, p} \cdot s_{t, c} \quad ; \quad \forall(t, c, p): t>1$

$$
\begin{array}{ll}
e_{t, c, p} \leq x_{t-1, c, L_{c}, p} & ; \forall(t, c, p): t>1 \\
e_{t, c, p} \leq s_{t, c} & ; \quad \forall(t, c, p): t>1 \\
e_{t, c, p} \geq x_{t-1, c, L_{c}, p}+s_{t, c}-1 & ; \quad \forall(t, c, p): t>1 \\
e_{t, c, p} \geq 0 & ; \quad \forall(t, c, p): t>1
\end{array}
$$

\subsection{Simplified model}

Under certain conditions, it is possible to reduce the number of variables and constraints of the previous model, resulting in a smaller model able to solve the same problem. As it was shown in Eq. (1), there is a cost associated with starting/stopping the pumping process in each polyduct of the network. This cost is usually high since it involves a change in the operation system of all the machinery used for that purpose. Furthermore, the interface losses are higher when the flow in the network is started or stopped, due to the transient rate of flow which occurs until it reaches a steady state. As a consequence, an optimal polyduct schedule should only use stops when strictly necessary. It can be translated to the optimality constraint shown in Eq. (21). In such a situation, Eq. (6) forces $s_{t, c}=1$ for all the unidirectional polyducts, and all these variables can be removed from the current model. In this case, one package must be pumped to each unidirectional polyduct at each period. Reversible polyducts still make use of Eq. (2), since these polyducts need to stop pumping at least through one of either sending direction and, in some cases, a reversal of the flow direction could be necessary. Hence, Eq. (2) is now defined only for reversible polyducts. The simultaneous usage of both sending directions in reversible polyducts is also forbidden through Eq. (3) but only defined for these polyducts:

$$
\sum_{p=1}^{P} y_{t, c, p}=1 \quad ; \quad \forall(t, c): c \notin C B
$$

Interface volume between adjacent packages with different products can now be considered by Eq. (23) instead of Eq. (4), and forbidden product sequences are now avoided by Eq. (24) instead of Eq. (5). Again, Eqs. (23) and (24) are used only for unidirectional polyducts, since the reversible ones still work with Eqs. (4) and (5):

$$
\begin{array}{ll}
v_{t, c, p, p^{\prime}} \geq V C_{p, p^{\prime}} \cdot\left(y_{t-1, c, p}+y_{t, c, p^{\prime}}-1\right) & ; \forall\left(t, c, p, p^{\prime}\right): t>1, c \notin C B \\
v_{1, c, p, p^{\prime}} \geq V C_{p, p^{\prime}} \cdot\left(x o_{c, 1, p}+y_{1, c, p^{\prime}}-1\right) & ; \forall\left(c, p, p^{\prime}\right): c \notin C B \\
v_{t, c, p, p^{\prime}} \geq 0 & ; \quad \forall\left(t, c, p, p^{\prime}\right): c \notin C B \\
y_{t-1, c, p}+y_{t, c, p^{\prime}} \leq 1 \quad ; \quad \forall\left(t, c, p, p^{\prime}\right): t>1, c \notin C B,\left(p, p^{\prime}\right) \in S \\
x o_{c, 1, p}+y_{1, c, p^{\prime} \leq 1} \quad ; \quad \forall\left(c, p, p^{\prime}\right): c \notin C B,\left(p, p^{\prime}\right) \in S
\end{array}
$$

Now, the set of constraints used for tracking inventory product at each node during the planning horizon is composed by Eq. (12) for source nodes and the constraints shown in Eqs. (24) and (25) for intermediate and destination nodes, respectively. These constraints replace the ones shown in Eqs. (13) and (14) for all the unidirectional polyducts. Eqs. (13) and (14) still work in the simplified model but are only defined for reversible polyducts. As it can be seen, these constraints can now be written without the variables $x$. Then, in this case, constraints (6)-(10), related to the package tracking on the network, are only defined for reversible polyducts and all the $x$ variables defined for unidirectional polyducts can be removed from the current model. This model also uses Eq. (11) to keep inventory product at each node within its maximum and minimum allowed levels and uses Eqs. (15) and (16) to fulfill the market demands at consumer nodes. Finally, the simplified model also includes Eqs. (17)-(20), defined for the linearization of all the nonlinear terms of the model, but they are only applied to reversible polyducts. 


$$
\begin{aligned}
& \begin{array}{c}
a_{t, n, p}=a_{t-1, n, p}-\sum_{c \in C O_{n}} y_{t, c, p}+\sum_{\substack{c \in C I_{n} \\
c \notin C B}} x o_{c, L_{c}+1-t, p}+\sum_{\substack{c \in C I_{n} \\
t \leq L_{c}}} y_{t-L_{c}, c, p} \quad ; \quad \forall(t, n, p): t>1, n \in N I \\
c \notin C B \\
t>L_{C}
\end{array}
\end{aligned}
$$

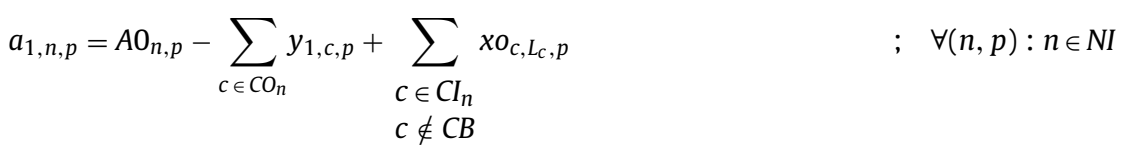

$$
\begin{aligned}
& a_{t, n, p}=a_{t-1, n, p}+\sum_{c \in C I_{n}} x o_{c, L_{c}+1-t, p}+\sum_{c \in C I_{n}} y_{t-L_{c}, c, p}-q m_{t, n, p} \quad ; \quad \forall(t, n, p): t>1, n \in N D \\
& c \notin C B \quad c \notin C B \\
& t \leq L_{C} \quad t>L_{C} \\
& \begin{aligned}
a_{1, n, p}=A 0_{n, p}+ & \sum_{\substack{c \in C I_{n} \\
c \notin C B}} x o_{c, L_{c}, p}-q m_{1, n, p} \\
& c \notin C \text {. }
\end{aligned} \\
& \text {; } \forall(n, p): n \in N D
\end{aligned}
$$

The simplified model should only be used in a high demand scenario and when the pumping cost is very low compared to start/ stop costs. Otherwise, the complete model should be used, since fulfillment of depot demands would not require pump operations during the entire planning horizon. If a high demand does not exist, the use of the simplified model would deliver an excessive number of product packages to depots and the additional inventory and pumping costs may surpass the savings in pipeline restarting costs. Moreover, the simplified model could lead to constant depletion or an increase of inventory product at intermediate nodes when the number of incoming and outgoing connections does not coincide. Hence, a previous analysis of the data specific to the problem has to be done before using the simplified model. At any rate, the complete model could solve any situation, but with a higher computational cost than that required by the simplified model. To illustrate this idea, several scenarios are solved in the next section.

\section{Numerical examples}

The proposed MILP approaches will be illustrated by solving an application example under several scenarios. The first scenario illustrates the utility of the complete model, while the second and third illustrate the utility of the simplified model. All the scenarios involve the network shown in Fig. 2 transporting four refined petroleum products (P1: gasoline; P2: diesel oil; P3: LPG;
P4: jet fuel) from two sources (N1-N2) to three distribution terminals (N5-N7). There are also two intermediate nodes (N3-N4) connecting sources to destinations with different polyducts. Products within these intermediate nodes can flow in both directions through a reversible polyduct. Thanks to this reversible polyduct it is possible that for the same planning horizon a product only available at node $N 2$ could arrive at node $N 5$ at the same time that the product only available at node $N 2$ could arrive at node $N 7$. All the examples were solved on an Intel Xeon IV $2.8 \mathrm{GHz} / 2$ GB RAM processor with CPLEX using ILOG OPL Studio 4.2 (ILOG Inc., 2006). A relative MIP gap tolerance equal to $1 \times 10^{-4}$ and an integrity tolerance of $1 \times 10^{-5}$ were adopted in all examples.

Common data for all the scenarios are shown in Table 1 . This table shows lower and upper limits for all depots in the network together with their initial values and the inventory cost. These data together with the demand for all the scenarios are selected to force the pumping of the product through the reversible polyduct in both directions. The demand must be fulfilled at the end of the planning horizon, composed by 20 time periods of length $\Delta=5 \mathrm{~h}$ $(100 \mathrm{~h})$. Consequently, the problem dimensions are $N=7$ nodes, $C=8$ connections, $P=4$ products and $T=20$ periods. The length of

\begin{tabular}{|c|c|c|c|c|c|c|c|c|}
\hline \multirow[t]{2}{*}{ Product } & \multirow[t]{2}{*}{ Parameter } & \multicolumn{7}{|c|}{ Node Ni (S: source, I: intermediate, D: destination) } \\
\hline & & $\mathrm{N} 1(\mathrm{~S})$ & $\mathrm{N} 2(\mathrm{~S})$ & N3(I) & $\mathrm{N} 4(\mathrm{I})$ & N5(D) & N6(D) & N7(D) \\
\hline \multirow{4}{*}{ P1 } & Min capacity $\left(V P \mathrm{~m}^{3}\right)$ & 5 & 5 & 2 & 2 & 2 & 2 & 2 \\
\hline & Max capacity $\left(V P \mathrm{~m}^{3}\right)$ & 40 & 40 & 30 & 30 & 20 & 20 & 20 \\
\hline & Initial state $\left(V P \mathrm{~m}^{3}\right)$ & 20 & 5 & 15 & 2 & 10 & 10 & 10 \\
\hline & Inventory cost $\left(\mathrm{US} \$ /\left(\mathrm{m}^{3} \mathrm{~h}\right)\right)$ & 0.006 & 0.006 & 0.009 & 0.009 & 0.012 & 0.012 & 0.012 \\
\hline \multirow{4}{*}{ P2 } & Min capacity $\left(V P \mathrm{~m}^{3}\right)$ & 5 & 5 & 2 & 2 & 2 & 2 & 2 \\
\hline & Max capacity $\left(V P \mathrm{~m}^{3}\right)$ & 40 & 40 & 30 & 30 & 20 & 20 & 20 \\
\hline & Initial state $\left(V P \mathrm{~m}^{3}\right)$ & 20 & 20 & 15 & 15 & 10 & 10 & 10 \\
\hline & Inventory cost $\left(\mathrm{US} \$ /\left(\mathrm{m}^{3} \mathrm{~h}\right)\right)$ & 0.008 & 0.008 & 0.011 & 0.011 & 0.016 & 0.016 & 0.016 \\
\hline \multirow{4}{*}{ P3 } & Min capacity $\left(V P \mathrm{~m}^{3}\right)$ & 5 & 5 & 2 & 2 & 2 & 2 & 2 \\
\hline & Max capacity $\left(V P \mathrm{~m}^{3}\right)$ & 40 & 40 & 30 & 30 & 20 & 20 & 20 \\
\hline & Initial state $\left(V P \mathrm{~m}^{3}\right)$ & 5 & 20 & 2 & 15 & 10 & 10 & 10 \\
\hline & Inventory cost $\left(\mathrm{US} \$ /\left(\mathrm{m}^{3} \mathrm{~h}\right)\right)$ & 0.007 & 0.007 & 0.010 & 0.010 & 0.014 & 0.014 & 0.014 \\
\hline \multirow{4}{*}{ P4 } & Min capacity $\left(V P \mathrm{~m}^{3}\right)$ & 5 & 5 & 2 & 2 & 2 & 2 & 2 \\
\hline & Max capacity $\left(V P \mathrm{~m}^{3}\right)$ & 40 & 40 & 30 & 30 & 20 & 20 & 20 \\
\hline & Initial state $\left(V P \mathrm{~m}^{3}\right)$ & 20 & 20 & 15 & 15 & 10 & 10 & 10 \\
\hline & Inventory cost $\left(\mathrm{US} \$ /\left(\mathrm{m}^{3} \mathrm{~h}\right)\right)$ & 0.006 & 0.006 & 0.009 & 0.009 & 0.012 & 0.012 & 0.012 \\
\hline
\end{tabular}
all polyducts is $L=3$, measured in terms of the number of packages that a polyduct is able to store. A value of $V P=5000 \mathrm{~m}^{3}$ is used as the

Table 1

Common data for all the scenarios. 
Table 2

Scheduled production runs at each refinery.

\begin{tabular}{|c|c|c|c|c|c|c|c|}
\hline \multicolumn{4}{|c|}{ Refinery N1 } & \multicolumn{4}{|c|}{ Refinery N2 } \\
\hline Product & Volume $\left(V P \mathrm{~m}^{3}\right)$ & Rate $\left(\mathrm{m}^{3} / \mathrm{h}\right)$ & Time interval (h) & Product & Volume $\left(V P \mathrm{~m}^{3}\right)$ & Rate $\left(\mathrm{m}^{3} / \mathrm{h}\right)$ & Time interval (h) \\
\hline P1 & 5 & 1000 & $0-25$ & $\mathrm{P} 1$ & 5 & 1000 & $75-100$ \\
\hline P2 & 5 & 1000 & $25-50$ & $\mathrm{P} 2$ & 5 & 1000 & $0-25$ \\
\hline P3 & 5 & 1000 & $75-100$ & P3 & 5 & 1000 & $25-50$ \\
\hline P4 & 5 & 1000 & $50-75$ & P4 & 5 & 1000 & $50-75$ \\
\hline
\end{tabular}

Table 3

Initial content and operational state of each polyduct.

\begin{tabular}{lllllllll}
\hline Section & C1 & C2 & C3 & C4 & C5 & C6 & C7 & C8 \\
\hline 1 & P1 & P3 & P2 & P1 & P2 & P2 & P4 & P3 \\
2 & P1 & P3 & P2 & P1 & P2 & P2 & P4 & P3 \\
3 & P1 & P3 & P2 & P4 & P1 & P2 & P4 & P3 \\
State & ON & ON & ON & ON & ON & OFF & ON & ON \\
\hline
\end{tabular}

unit package volume. Therefore, the pumping rate is $1000 \mathrm{~m}^{3} / \mathrm{h}$. The pumping cost, $C_{c, p}$, is usually proportional to the polyduct length, and in this case it is set to $L \mathrm{US} \$ / \mathrm{m}^{3}$ for all $c$ and $p$. Table 2 shows the scheduled production along the planning horizon at each refinery. Table 3 shows the initial content of the network (which product is contained inside each section of each polyduct) together with its initial operational state (if each polyduct is initially working). Finally, Table 4 shows the interface material cost and contact volume for each ordered pair of products. In this table, there are two forbidden product sequences (P1-P3) and (P3-P4), denoted with a $\times$ symbol.

\subsection{Scenario I-A: general case solved by the simplified model}

Table 5 shows the demand for all the consumer nodes (N5, N6 and N7) used in this first scenario. As it was said above, these demands, together with the data shown in Table 1 , have been selected to force the pumping of product through the reversible polyduct in both directions. The start/stop cost factor $C T_{C}$ is set to 100,000 US\$ for all polyducts. First, this scenario is solved by the simplified model. This model has 2959 variables and 5360 constraints. The optimal solution is found after $2348 \mathrm{~s}$ of computation and has a total cost of 3,512,280 US\$. This cost corresponds to $1,995,000$ US\$ due to the pumping cost, 200,000 US\$ due to the start/stop cost, 41,400 US\$ due to the reprocessing of 13 transmixes and $1,275,880$ US\$ due to the inventory cost at all nodes of the network.

Fig. 5 shows the optimal pumping sequence reached by the simplified model for all the polyducts of the network. White has been

Table 4

Contact characteristics.

\begin{tabular}{|c|c|c|c|c|c|c|c|c|}
\hline \multirow[t]{2}{*}{ Product } & \multicolumn{4}{|c|}{ Contact volume $\left(\mathrm{m}^{3}\right)$} & \multicolumn{4}{|c|}{ Reprocessing cost $\left(\mathrm{US} \$ / \mathrm{m}^{3}\right)$} \\
\hline & P1 & P2 & P3 & P4 & P1 & P2 & P3 & P4 \\
\hline P1 & 0 & 30 & $\times$ & 35 & 0 & 100 & 100 & 100 \\
\hline P2 & 30 & 0 & 37 & 38 & 100 & 0 & $\times$ & 100 \\
\hline P3 & $\times$ & 37 & 0 & $\times$ & $\times$ & 100 & 0 & $\times$ \\
\hline P4 & 35 & 38 & $\times$ & 0 & 100 & 100 & $\times$ & 0 \\
\hline
\end{tabular}

Table 5

Demand $\left(V P \mathrm{~m}^{3}\right)$ for Scenarios I and II.

\begin{tabular}{llll}
\hline Product & D1 (N5) & D2 (N6) & D3 (N7) \\
\hline P1 & 10 & 10 & 10 \\
P2 & 10 & 10 & 10 \\
P3 & 10 & 10 & 10 \\
P4 & 10 & 10 & 10 \\
\hline
\end{tabular}

used to denote a stop on the pumping sequence. As it can be seen, products $\mathrm{P} 1$ and $\mathrm{P} 3$ are never in contact since this is a forbidden sequence. The same happens with products P3 and P4. Pumping should be continuous in all the polyducts, whenever it is possible, in the same conditions given at the beginning of the planning horizon. The initial state is defined by the previously pumped product, under the symbol shown in Fig. 5, and by the state shown in Table 3. Note that connections C3 and C6 correspond to the same reversible polyduct. Connection $\mathrm{C} 3$ starts pumping at the beginning of the planning horizon. First, two packages of P1 are sent through this polyduct between periods 1-2 from N3 to N4 (connection C3) followed by three packages of P2 to pump the previous ones to $\mathrm{N} 4$, and then another eight packages of P3 are sent through the same polyduct between periods 13-20 from N4 to N3 (connection C6). In other words, this polyduct is able to stop pumping through one of its sending directions when it is necessary. Such stoppage at C3 followed by a starting at C6 is strictly necessary in order to deliver the demanded amount of P1 to N7 and P3 to N5. All the unidirectional polyducts do not stop pumping since this pumping sequence was calculated by the simplified model in this example.

Note that some product fragmentations are needed to fulfill all the constraints. For example, if connection C3 pumps the sequence $5 \mathrm{P} 1$ instead of 2P1-3P2, product $\mathrm{P} 3$ pumped through $\mathrm{C} 6$ at period 13 would be in contact with product $P 1$, which can not be since this is a forbidden sequence. A similar situation happens at connections $\mathrm{C} 7$ and $\mathrm{C} 8$. So, the existence of forbidden product sequences combined with maximum deadlines to meet customer demands makes the problem of finding the best pumping sequence a non-trivial matter. Fig. 6 shows the variations of product inventory over time at each node associated with the pumping sequence shown in Fig. 5. As can be seen, all inventory levels remain between their permissible ranges.

\subsection{Scenario I-B: general case solved by the complete model}

Given the characteristics of Scenario I, it would be possible to stop pumping through any polyduct, since the cost for doing so is not very high and the amount of product in demand at each consumer node does not require continuous pumping from the sources. Therefore, the simplified model could give non-optimal solutions, making it necessary to solve this scenario by the complete model. This model has 5245 variables and 13,086 constraints. The optimal solution is found after $19,475 \mathrm{~s}$ of computation and has a total cost of $2,803,800$ US\$. This cost corresponds to 840,000 US\$ due to the pumping cost, 700,000 US\$ due to the start/stop cost, 41,400 US\$ due to the reprocessing of 13 transmixes and 1,222,400 US\$ due to the inventory cost at all nodes of the network. Table 6 shows a comparison among the cost factors shown in Eq. (1) associated with the optimal solution found by each model for Scenario I. As it can be seen, the cost savings in pumping and inventory costs using the complete model surpass the increase of start/stop costs.

The quality of the solution given in the simplified model can be measured by the gap between its optimal cost achieved and its lower limit which is given in the solution reached by the complete model. Table 7 shows how the simplifications made in this model lead to a $20.17 \%$ difference from the optimal cost. 


\begin{tabular}{|c|c|c|c|c|c|c|c|c|c|c|c|c|c|c|c|c|c|c|c|c|c|}
\hline & & \multicolumn{20}{|c|}{ Periods } \\
\hline Connections & $\bullet$ & 1 & 2 & 3 & 4 & 5 & 6 & 7 & 8 & 9 & 10 & 11 & 12 & 13 & 14 & 15 & 16 & 17 & 18 & 19 & 20 \\
\hline \multicolumn{22}{|c|}{ A } \\
\hline \multicolumn{22}{|l|}{$\mathrm{C} 2(\mathrm{~N} 2-\mathrm{N} 4)$} \\
\hline C3 (N3-N4) Bidir. & 典 & +8 & 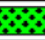 & 田 & 开 & 且 & & & & & & & & & & & & & & & \\
\hline C4 (N3-N5) & $\%$ & $\%$ & & & & & 型 & 亚 & 型 & 㙉 & 重 & 重 & 需 & 典 & 典 & 型 & & & & & \\
\hline C5 (N3-N6) & 無 & $\%$ & $6 \%$ & $\because$ & $\because$ & $\because$ & 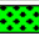 & $\because 8$ & $\because$ & $\because 6$ & $\because 6$ & $\because 6$ & $\because 6$ & $\because 6$ & $\because 6$ & $\because 6$ & $\because 6$ & $\because 6$ & $\because 6$ & $\because 6$ & $\because 6$ \\
\hline C6 (N4-N3) Bidir. & 䒜 & & & & & & & & & & & & & & & & & & & & \\
\hline C7 (N4-N6) & & 皿 & & & & & & & & & & & & & & & & & & & \\
\hline C8 (N4-N7) & & & & & 4 & 井 & $\cdots$ & & & & & & & & & & & & & & \\
\hline
\end{tabular}

Fig. 5. Optimal pumping sequence reached by the simplified model for Scenario I.
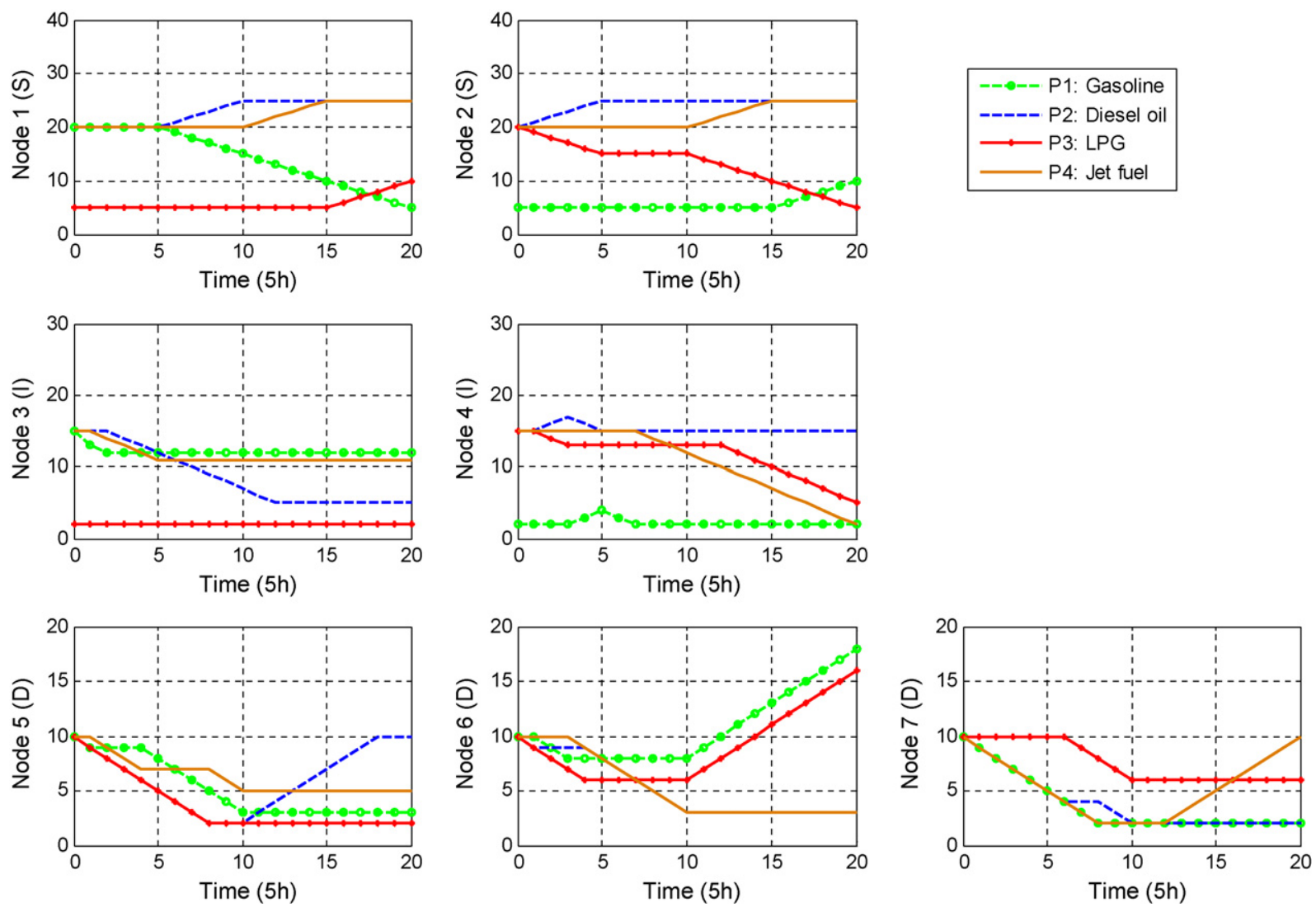

Fig. 6. Variations of inventory levels over time for Scenario I-A.

However, the simplified model is able to find its optimal solution in $2348 \mathrm{~s}$ compared with $19,475 \mathrm{~s}$ in the complete model. Thus, in scenarios where both models give the same solution, the simplified model could speed up the convergence towards the optimal solution.
Fig. 7 gives the pumping sequence for the complete model showing how in this case some stops are performed in order to minimize the overall cost. Fig. 8 shows the variations of product inventory over time at each node. Again, all inventory levels remain between their permissible ranges, trying to remain close to

Table 6

Cost factors associated to the optimal solution found by each model for Scenario I.

\begin{tabular}{|c|c|c|c|c|c|}
\hline Model & Obj1 (US\$) & Obj2 (US\$) & Obj3 (US\$) & Obj4 (US\$) & Total (US\$) \\
\hline Simplified model & $1,995,000$ & 200,000 & 41,400 & $1,275,880$ & $3,512,280$ \\
\hline Complete model & 840,000 & 700,000 & 41,400 & $1,222,400$ & $2,803,800$ \\
\hline
\end{tabular}

Table 7

Inventory cost of the optimal solutions reached for Scenario I.

\begin{tabular}{|c|c|c|c|c|}
\hline Model & Optimal cost (US\$) & Lower bound (US\$) & Difference (US\$) & Gap (\%) \\
\hline Simplified model & $3,512,280$ & $2,803,800$ & 708,480 & $20.17 \%$ \\
\hline Complete model & $2,803,800$ & $2,803,800$ & 0 & $0.00 \%$ \\
\hline
\end{tabular}




\begin{tabular}{|c|c|c|c|c|c|c|c|c|c|c|c|c|c|c|c|c|c|c|c|c|c|}
\hline & & \multicolumn{20}{|c|}{ Periods } \\
\hline Connections & $\diamond$ & 1 & 2 & 3 & 4 & 5 & 6 & 7 & 8 & 9 & 10 & 11 & 12 & 13 & 14 & 15 & 16 & 17 & 18 & 19 & 20 \\
\hline \multicolumn{22}{|l|}{$\mathrm{C} 1(\mathrm{~N} 1-\mathrm{N} 3)$} \\
\hline \multicolumn{22}{|l|}{$\overline{\mathrm{C} 2}$ (N2-N4) } \\
\hline C3 (N3-N4) Bidir. & Hit & $\because \because$ & $\because \because$ & III & III & II & 茾 & & & & & & & & & & & & & & \\
\hline C4 (N3-N5) & $\because \because$ & 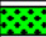 & $\because \because$ & $\because \%$ & $\therefore$ & $\because \%$ & & & & 䓝 & 型 & 型 & 茾 & 型 & 开 & 茾 & & & & & \\
\hline C5 (N3-N6) & 男 & $\because \because$ & $\because \because$ & $\because \%$ & $\because+$ & & & & & & & & & & & & & & & & \\
\hline C6(N4-N3) Bidir. & 草 & & & & & & & & & & & & & & & & & & & & \\
\hline C7 (N4-N6) & & 刑 & & & & & & & & & & & & & & & & & & & \\
\hline C8 (N4-N7) & & 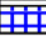 & 王 & 7 & & $\because$ & & & & & & & & & & & & & & & \\
\hline
\end{tabular}

Fig. 7. Optimal pumping sequence reached by the complete model for Scenario I.

their minimum possible values throughout the planning horizon in order to minimize the overall inventory cost.

\subsection{Scenario II: high start/stop cost}

Second scenario uses the same demand used for Scenario I shown in Table 5. However, in this case, the start/stop cost factor $C T_{c}$ is set to 500,000 US $\$$ for all polyducts. Given such a high cost factor $C T_{c}$, an optimal pumping schedule should only use stops when strictly necessary. In this case, it may only include reversal in the pumping direction at reversible polyducts. In such a situation, both the simplified and complete models give the same solution with a total cost of 3,512,280 US\$. This cost corresponds to $1,995,000$ US\$ due to the pumping cost, 200,000 US $\$$ due to the start/stop cost, 41,400 US $\$$ due to the reprocessing of 13 transmixes and 1,275,880 US\$ due to the inventory cost at all nodes of the network. Table 8 shows the problem dimensions for each model together with the CPU time needed to solve this example. As it can be seen from this table, the usage of the simplified model instead of the complete model reduces the problem dimensions approximately by half and the CPU time needed to reach the optimal solution decreases more than one order of magnitude.

Fig. 9 shows the pumping sequence for the optimal solution in this scenario. As it can be seen, all the unidirectional polyducts are continuously being pumped throughout the planning horizon since pumping cost is very low compared to start/stop costs. Fig. 10 shows the variations of product inventory over time at each node associated with the pumping sequence shown in Fig. 9. It also shows that all inventory levels remain between their permissible ranges.

\subsection{Scenario III: high demand pattern}

The third scenario consists of a high demand pattern. Table 9 shows the demand for all the consumer nodes (N5, N6 and N7). These demands together with the data shown in Table 1 have been selected again to force the pumping of the product through the
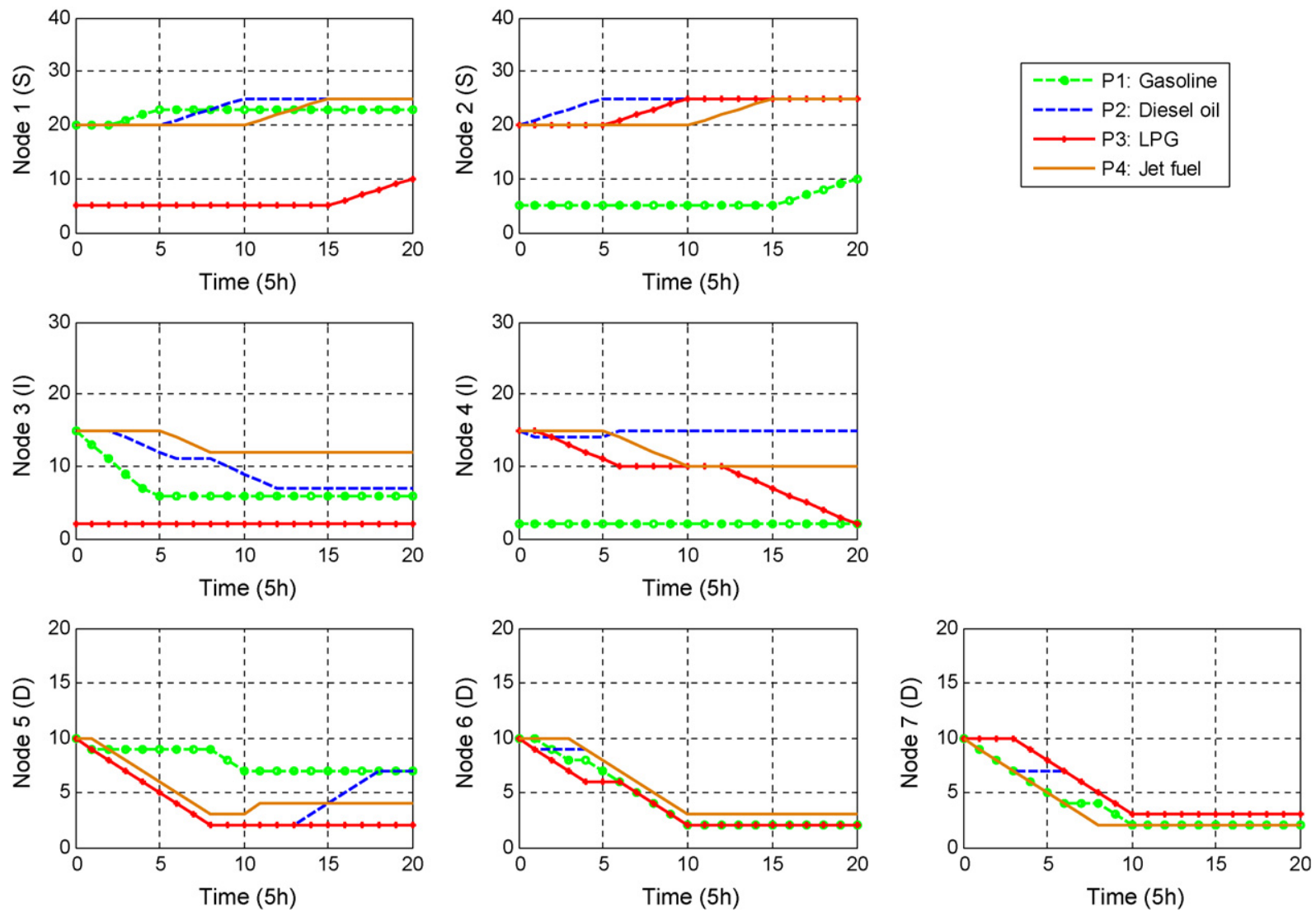

Fig. 8. Variations of inventory levels over time for Scenario I-B. 
Table 8

Problem dimensions and CPU time associated to each model for Scenario II.

\begin{tabular}{|c|c|c|c|c|}
\hline Model & Constraints & Variables & Non-zero coefficients & CPU Time (s) \\
\hline Simplified model & 5360 & 2959 & 17,832 & 889 \\
\hline Complete model & 13,086 & 5245 & 39,507 & 9227 \\
\hline
\end{tabular}

\begin{tabular}{|c|c|c|c|c|c|c|c|c|c|c|c|c|c|c|c|c|c|c|c|c|c|}
\hline & & \multicolumn{20}{|c|}{ Periods } \\
\hline Connections & $\bullet$ & 1 & 2 & 3 & 4 & 5 & 6 & 7 & 8 & 9 & 10 & 11 & 12 & 13 & 14 & 15 & 16 & 17 & 18 & 19 & 20 \\
\hline $\mathrm{Cl}(\mathrm{N} 1-\mathrm{N} 3)$ & $\Leftrightarrow$ & & 0 & $\cdots$ & $\cdots$ & & & & $\because$ & & $\because$ & $\because$ & $\because$ & 0 & & $\theta \%$ & $\because$ & $\cdots$ & 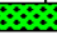 & & $\Leftrightarrow$ \\
\hline $\mathrm{C} 2(\mathrm{~N} 2-\mathrm{N} 4)$ & & & & & & & & & & & & & & & & & & & & & \\
\hline C3 (N3-N4) Bidir. & 国 & $\%$ & $\%$ & 田 & 开 & 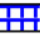 & & & & & & & & & & & & & & & \\
\hline C4 (N3-N5) & $\because ;$ & 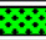 & $\%$ & $\because ;$ & $\%$ & & 王 & 王 & 王 & 开 & 曹1 & 王 & 王 & 王王 & 开 & 型 & & & & & \\
\hline $\mathrm{C} 5(\mathrm{~N} 3-\mathrm{N} 6)$ & 四 & 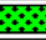 & $\%$ & $\because \%$ & $\%$ & $\because$ & $\%$ & $\%$ & $\%$ & $\approx$ & $\%$ & $\%$ & $\%$ & 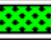 & 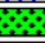 & 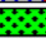 & 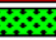 & $\%$ & $\%$ & $* \%$ & 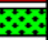 \\
\hline C6 (N4-N3) Bidir. & 曲覀 & & & & & & & & & & & & & & & & & & & & \\
\hline $\mathrm{C7}(\mathrm{N} 4-\mathrm{N} 6)$ & & 册 & & & & & & & & & & & & & & & & & & & \\
\hline $\mathrm{C} 8$ (N4-N7) & & & & & 开 & & & & & & & & & & & & & & & & \\
\hline
\end{tabular}

Legend: $\quad$ P1 $\%$ P2 冊 P3 $\quad$ P4 $\quad$ P4

Fig. 9. Optimal pumping sequence reached by both models for Scenario II.
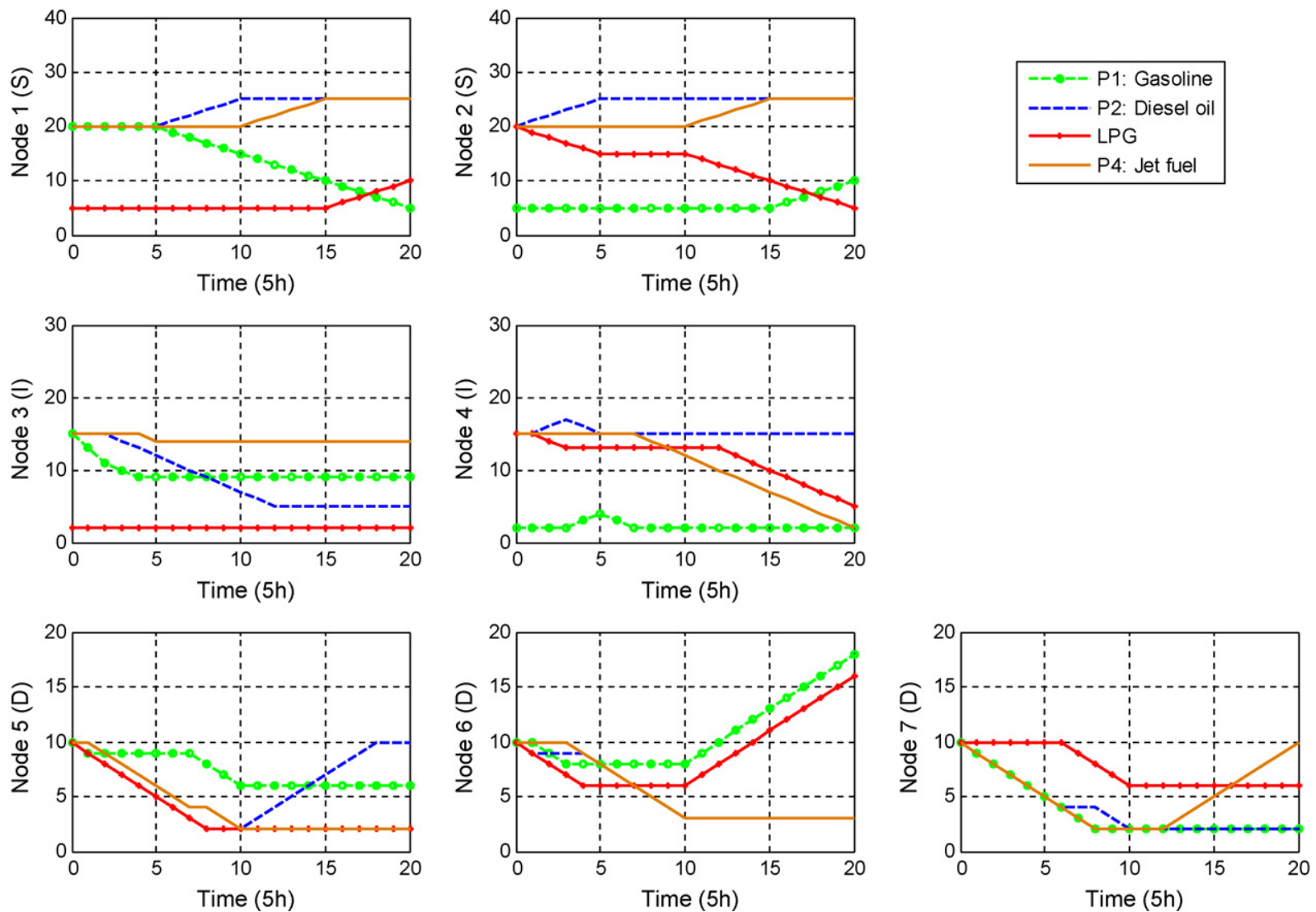

Fig. 10. Variations of inventory levels over time for Scenario II.

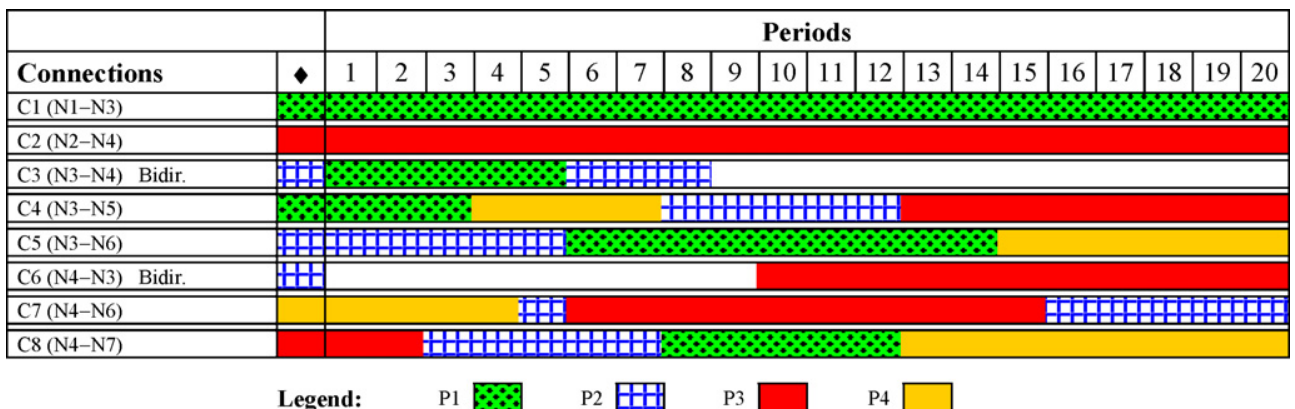

Fig. 11. Optimal pumping sequence reached by both models for Scenario III. 

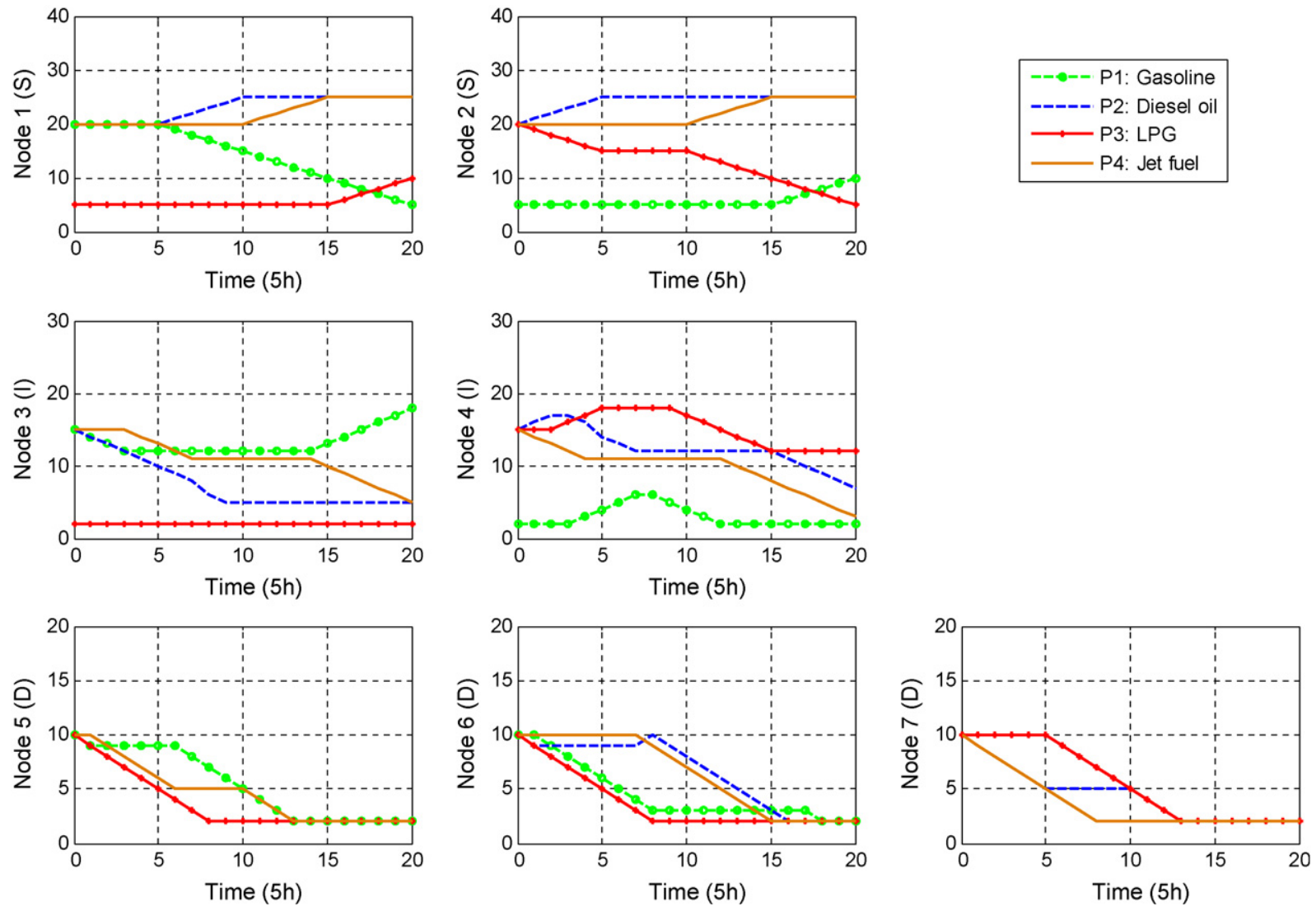

Fig. 12. Variations of inventory levels over time for Scenario III.

Table 9

Demand $\left(V P \mathrm{~m}^{3}\right)$ for Scenario III.

\begin{tabular}{llll}
\hline Product & D1 (N5) & D2 (N6) & D3 (N7) \\
\hline P1 & 13 & 18 & 13 \\
P2 & 13 & 18 & 13 \\
P3 & 13 & 18 & 13 \\
P4 & 13 & 18 & 13 \\
\hline
\end{tabular}

reversible polyduct in both directions. The start/stop cost factor $C T_{C}$ has been set again to 100,000 US $\$$ for all polyducts. However, the high demand imposed at this scenario requires continuous pumping during the entire planning schedule. Thus, this scenario can be solved again by the simplified model to get the same optimal solution given by the complete model. In this case, the total cost associated to this solution is 4,312,270 US\$. This cost corresponds to $1,995,000$ US\$ due to the pumping cost, $1,000,000$ US\$ due to the start/stop cost, 41,400 US\$ due to the reprocessing of 13 transmixes and 1,275,870 US\$ due to the inventory cost at all nodes of the network. Fig. 11 shows the pumping sequence for the optimal solution in this scenario. Again, all the unidirectional polyducts are continuously being pumped throughout the planning horizon in order to meet demands at consumer nodes. Finally, Fig. 12 shows the variations of product inventory over time at each node associated with the pumping sequence shown in Fig. 11. Once again, all inventory levels remain between their permissible ranges and depots at destination nodes tend to remain close to their minimum values to minimize the overall inventory cost.

\section{Conclusions}

This paper proposes a MIP model for planning the transportation of multiple petroleum products in a multi-pipeline system. On a logistic level, the problem in such systems is how to plan the way in which different products taken from refineries are temporally transported to meet customer demands at delivery points in due time. Product balance at intermediate nodes is the most difficult process to model; however, it can be easily modeled assuming a discrete transport approach that divides both the planning horizon into time intervals of equal duration and the individual polyducts into packages of equal volume containing a single product. The model proposed in this paper considers the minimization of the total cost composed of four different terms: pumping, start/stop, reprocessing and inventory costs. Under certain conditions, it is possible to reduce the number of variables and constraints of the proposed model, resulting in a smaller model able to solve the same problem. This simplified model should only be used in a high demand scenario and when the pumping cost is very low compared to start/stop costs. Otherwise, the complete model should be used, since fulfillment of depot demands would not require pump operations during the entire planning horizon.

To illustrate the model applications, a numerical example was solved under several scenarios. Data for all the examples were selected to force the pumping of product through the reversible polyduct in both directions. The first scenario shows how when low demand and start/stop costs are given, the complete model should be used, since this scenario does not require continuous pumping from the sources, and as a consequence the simplified model could give non-optimal solutions. However, if there is a high start/stop cost (Scenario II) or a high demand pattern (Scenario III), the simplified model is able to reach the same optimal solution as given by the complete model within more than one order of magnitude less time.

Finally, notice how in Scenario I-A, the complete model has 5245 variables and 13,086 constraints. In this general case, the MIP algorithm was running over 20,000 s to reach the optimal solution with 
this model. This fact gives an idea of the complexity of the problem here considered. The problem addressed is a NP-hard combinatorial problem. For this reason, the authors are currently working on developing several metaheuristic algorithms to efficiently solve these kinds of problems by the models here proposed.

\section{Acknowledgments}

The authors would like to thank the Spanish Science and Technology Ministry for their support of project DPI2002-02924 and the Madrid Autonomous Community for their support of project S-0505/DPI/0391.

\section{References}

Cafaro, D. C., \& Cerdá, J. (2004). Optimal scheduling of multiproduct pipeline systems using a nondiscrete MILP formulation. Computers and Chemical Engineering, 28, 2053-2068.

Cafaro, D. C., \& Cerdá, J. (2008). Dynamic scheduling of multiproduct pipelines with multiple delivery due dates. Computers and Chemical Engineering, 32, 728-753.
Cruz, J. M., Andrés, B., Herrán, A., Besada, E., \& Fernández, P. (2003). Multiobjective optimization of the transport in oil pipelines networks. In Proceedings of the 9th IEEE International Conference on Emerging Technologies and Factory Automation, vol. 1 (pp. 566-573)

Cruz, J. M., Herrán, A., Risco, J. L., \& Andrés, B. (2005). Hybrid heuristic and mathematical programming in oil pipelines networks: Use of immigrants. Journal of Zhejiang University Science, 6A(1), 9-19.

ILOG Inc. (2006). ILOG OPL Studio 4.2 users manual. 1080 Linda Vista Ave., Mountain View, CA 94043. http://www.ilog.com.

Mirhassani, S. A., \& Ghorbanalizadeh, M. (2008). The multiproduct pipeline scheduling system. Computers and Mathematics with Applications, 56(4), 891-897.

Rejowski, R., Jr., \& Pinto, J. M. (2003). Scheduling of a multiproduct pipeline system. Computers and Chemical Engineering, 27, 1229-1246.

Rejowski, R., Jr., \& Pinto, J. M. (2004). Efficient MILP formulations and valid cuts for multiproduct pipeline scheduling. Computers and Chemical Engineering, 28, 1511-1528.

Rejowski, R., Jr., \& Pinto, J. M. (2008). A novel continuous time representation for the scheduling of pipeline systems with pumping yield rate constraints. Computers and Chemical Engineering, 32, 1042-1066.

Sasikumar, M., Prakash, P. R., Patil, S. M., \& Ramani, S. (1997). PIPES: A heuristic search model for pipeline schedule generation. Knowledge-Based Systems, 10 , 169-175.

Techo, R., \& Holbrook, D. L. (1974). Computer scheduling the worlds biggest product pipeline. Pipeline and Gas Journal, 4, 27. 